Antioxidant activity, photosynthetic rate, and

\title{
Spectral mass in bean Plants (Phaseolus vulgaris L.) in Response to Stress Defense Activators
}

\author{
Nazario Francisco Francisco ${ }^{1}$, Gabriel Gallegos Morales ${ }^{2 *}$, Adalberto \\ Benavides Mendoza ${ }^{3}$, Francisco Daniel Hernández Castillo², Yisa María \\ Ochoa Fuentes ${ }^{2}$, Francisco Castillo Reyes ${ }^{4}$, Raúl Rodríguez Herrera ${ }^{5}$
}

\begin{abstract}
${ }^{1}$ Departamento de Agricultura Sustentable y Protegida, Universidad Tecnológica de Tehuacán, prolongación de la 1 sur No. 1101, San Pablo Tepetzingo, Tehuacán, Puebla

${ }^{2}$ Departamento de Parasitología Agrícola y ${ }^{3}$ Departamento de Horticultura, Universidad Autónoma Agraria Antonio Narro, Calzada Antonio Narro 1923, Buenavista, Saltillo, Coahuila, México

${ }^{4}$ Campo Experimental Saltillo, INIFAP, Carretera Saltillo-Zacatecas km 342+119, Colonia Hacienda de Buenavista, Saltillo, Coahuila, México

${ }^{5}$ Facultad de Ciencias Químicas, Universidad Autónoma de Coahuila, Boulevard Venustiano Carranza S/N, Colo nia República, Saltillo, Coahuila, México

*Author for correspondence. Email: gabgalmor@yahoo.com.mx; ggalmor@uaaan.mx
\end{abstract}

\begin{abstract}
An increase in antioxidant activity is a common response in plants as a defense mechanism against biotic and abiotic stress factors, such response is also generated with the exogenous application of "defense activators", which have negative effects on plant metabolism. In this work, bean plants (Phaseolus vulgaris L.) $c v$. Pinto Nacional were treated with jasmonic acid (0.5 mM), salicylic acid (2 mM), Trichoderma asperellum $\left(10^{5}\right.$ spores $\left./ \mathrm{ml}\right)$, and Bacillus pumilus $\left(10^{5} \mathrm{CFU} / \mathrm{mL}\right)$, in order to determine the level of structural and metabolic response of the plants. On the seventh day after the application of the treatments, it was measured the enzymatic activity of catalase (CAT), peroxidase (POX), and superoxide dismutase (SOD). In addition, leaf impressions were taken to measure the stomatal opening and conductance, photosynthetic rate, and the mass spectrum (mass/charge, $m / z$ ). The antioxidant activity increased in plants treated with jasmonic acid and $T$. asperellum, which in turn significantly increased the stomatal opening and conductance, and photosynthetic rate. The mass profile showed that the plants treated with T. asperellum have a greater quantity of masses/charge, of which some had statistically highly significant difference according to the means test Tukey ( $p<0.05)$. It is concluded that some defense activators such as jasmonic acid and T. asperellum increase the antioxidant activity, defense response that concurs with the high photosynthetic and metabolic rate in bean plants.
\end{abstract}

Keywords-Bacillus pumilus, Trichoderma asperellum, jasmonic and salicylic acid.

\section{INTRODUCTION}

Induced resistance is a "physiological state" in which there is an increase in the defensive capacity of plants as a natural response to different biotic and abiotic stimuli, it is also achieved with the exogenous application on the vegetable epidermis of some chemical compounds, microorganisms, as well as with metabolites produced by the same plants during tolerance to stress situations (Pieterse et al., 2014). In plant protection against phytopathogens, beneficial microorganis ms are frequently used, such as the antagonists Trichoderma spp., and growth-promoting bacteria from the genus Bacillus spp. (Bisen et al., 2016; Niu et al., 2016). Similarly, chemical compounds, natural and synthetic, are used to increase the defensive capacity of economically important plants (Lin et al., 2009). The exogenous application of salicylic acid in order to induce " Systemic Acquired Resistance " and jasmonic acid for "Induced Systemic Resistance" have been valuable as experimental controls in tests on edible plant species as well as shrubby plants (Moreira et al., 2009; Hayat et al., 2010).

Enzymatic activity, as a biochemical defense mechanism, is a process that is presented to face the attack of pathogens, this occurs in response to the release of reactive oxygen species (ROS), a process known as "oxidative burst" (Bolwell and Daudi, 2009). ROS are toxic intermediates that result from the reduction of molecular oxygen in the plant-pathogen interaction, such as hydrogen peroxide $\left(\mathrm{H}_{2} \mathrm{O}_{2}\right)$ and superoxide anion $\left(\mathrm{O}_{2}^{-}\right)$ (Helepciuc et al., 2014). Faced with this situation, the 
plants generate antioxidant enzymes that prevent the damage they can cause to themselves. Some of the enzymes that increase considerably, are catalase and peroxidase, which convert hydrogen peroxide into oxygen and water, and superoxide dismutase that transforms the superoxide anion to molecular oxygen and hydrogen peroxide (Helepciuc et al., 2014). These enzymes increase their synthesis considerably with the exogenous application of defense activators (Hafez and Seleiman, 2017).

The response of legumes to defense activators is very variable, and includes the formation of structural barriers as part of the first line of defense of plants (Oliveira et al., 2016). It has been proven that the induction of defense implies a metabolic cost for the plants. For example, there is evidence that the rupture of cells by pathogenic infections involves the formation of infection structures and have a strong impact on the water relation of plants (Grimmer et al., 2012); which is closely related to the stomatal behavior. The monitoring of the opening and stomatal conductance of the plants during the induction events turns out to be of great importance. A negative affectation by the defense inducers would cause the alteration of important physiological processes such as photosynthesis.

On the other hand, since it is known that plants modify their metabolic and physiological processes when they interact with various biotic and abiotic factors, the interest in elucidating such processes has been addressed through the use of "omic" sciences in plant species. Metabolomics is presented as a science that studies reactive metabolites, intermediates, or products of biochemical reactions mediated by enzymes. Ionization based mass spectrometry can be considered as a standard technique in metabolomics and is the ion source that offers the advantage that variables measured as mass charge, $\mathrm{m} / \mathrm{z}$ can be directly linked to a metabolite by its atomic mass; and this in turn, with the presence of active metabolites related to plant defense (Massange-Sanchez et al., 2015). In order to facilitate this task, there are application software linked to databases that identify metabolites from a list of spectral masses with high precision (Winkler, 2015). The description of the metabolomic profile of plant species of economic importance under the effect of chemical and microbial defense activators constitutes an important tool for the detection of metabolites that participate in plant resistance. Bean (Phaseolus vulgaris L.) is a crop of great economic importance that can be attacked by different phytopathogens, among them bacterial diseases, therefore it represents a model for the studies that allow to detect the participation of metabolites in the resistance to the diseases within the family of the legumes.
This work was carried out in order to determine the antioxidant activity and the changes induced in the metabolism of bean plants (Phaseolus vulgaris L.) in response to the defense activators Trichoderma asperellum, Bacillus pumilus, jasmonic acid, and salicylic acid.

\section{MATERIALS AND METHODS}

\subsection{Plant material}

Seeds of bean cv. Pinto Nacional were sown in black polyethylene pots with peat as substrate, which was previously sterilized in an autoclave at $120^{\circ} \mathrm{C}$ during 15 minutes.

\subsection{Preparation of treatments}

The treatments applied were: salicylic acid at $2 \mathrm{mM}$ (SA) (Sigma-Aldrich), jasmonic acid (JA) at $0.5 \mathrm{mM}$ (SigmaAldrich), Trichoderma asperellum (Ta) (10 spores $/ \mathrm{ml})$, and Bacillus pumilus (B) $\left(10^{5} \mathrm{CFU} / \mathrm{mL}\right)$; previously identified strains (Castillo et al. 2011 and Guillén-Cruz et al. 2006). The treatments were applied to bean seedlings at 7 days after emergence and were sprayed on cotyledonary leaves. The pots with the plants were established in a greenhouse at a temperature of $28 \pm 5^{\circ} \mathrm{C}$ and $55 \pm 10 \%$ of relative humidity.

2.3 Preparation of samples and extract for determination of total soluble protein content.

Four plants were collected per treatment, 7 days after starting the experiment, which were dehydrated for 24 hours in a Labconco ${ }^{\circledR}$ lyophilizer. The protein extract was obtained by placing $0.2 \mathrm{~g}$ of the lyophilized tis sue in microcentrifuge tubes with $1.5 \mathrm{~mL}$ of phosphate buffer $\left(\mathrm{Na}_{2} \mathrm{HPO}_{4} / \mathrm{NaH}_{2} \mathrm{PO}_{4}\right) 0.1 \mathrm{M}$ at $\mathrm{pH} 7.0$, subsequently, it was microcentrifuged at $12,000 \mathrm{rpm}$ for $10 \mathrm{~min}$ at $4{ }^{\circ} \mathrm{C}$. The determination of total soluble protein was carried out with the Bradford method (Bradford, 1976). Bovine serum albumin was used as standard in protein quantification.

2.4 Antioxidant activity.

In order to determine the catalase activity (CAT), the reaction mixture was made with $0.1 \mathrm{~mL}$ of protein extract. The reaction was initiated with the addition of $1 \mathrm{~mL}$ of peroxide at $100 \mathrm{mM}$. The reaction was stopped with the addition of $0.4 \mathrm{~mL}$ of $5 \%$ sulfuric acid. The enzymatic activity was estimated by calculating the decomposition of the peroxide per $\mathrm{min} / \mathrm{mg}$ of protein. It was determined by measuring 2 reaction times, time 0 , and 1 minute of reaction at a wavelength of $275 \mathrm{~nm}$ in a spectrophotometer (Thermo-Spectronic, Biomate, USA). The specific activity was expressed in units/mg of protein. Peroxidase activity (POX) was measured with the methodology of Baskaran et al. (2009). The reaction mixture $(1.2 \mathrm{~mL})$ was prepared with $0.1 \mathrm{~mL}$ of protein extract, $0.5 \mathrm{~mL}$ of $100 \mathrm{mM}$ buffer, $0.2 \mathrm{~mL}$ of pyrogallol, 
and $0.2 \mathrm{~mL}$ of hydrogen peroxide. The reaction was stopped 1 minute later, with the addition of $5 \%$ sulfuric acid. The measurements were taken at a wavelength of $420 \mathrm{~nm}$. In both determinations, the same enzyme extract was used. The Superoxide Dismutase (SOD) activity was measured with a 19160 measuring kit (Sigma-Aldrich). The procedure was carried out following the protocol of the kit. For this determination, $20 \mu \mathrm{L}$ of each sample was deposited in the wells of the ELISA microplate, $200 \mu \mathrm{L}$ of the working solution of the kit was added. The mixture was shaken slightly to mix and then incubated at $37{ }^{\circ} \mathrm{C}$ for $20 \mathrm{~min}$. After this incubation time, $20 \mu \mathrm{L}$ of the enzyme solution of the kit was added. The absorbance of the mixture was read at $450 \mathrm{~nm}$ in a microplate reader and the SOD activity was calculated using the following equation:

SOD activity (inhibition rate $\%)=((($ blank $1-$ blank 3$)-$ (sample A - blank 2))/(blank 1 - blank 3)) x 100.

Where the blank 1 is a mixture of the working solution $(200 \mu \mathrm{L})$ and the enzymatic solution of the kit $(20 \mu \mathrm{L})$ containing $20 \mu \mathrm{L}$ of double distilled water. Blank 2 contained the plant extract $(20 \mu \mathrm{L})$ with the working solution $(200 \mu \mathrm{L})$ and the dilution buffer $(20 \mu \mathrm{L})$, whereas blank 3 was added with distilled water $(20 \mu \mathrm{L})$ plus the working solution and the enzymatic solution in the same amount.

2.5 Measurement of stomatal conductance, photosynthetic rate, and stomatal opening.

The stomatal opening and conductance, and the photosynthetic rate, were measured on the seventh day of the experiment in 9 plants per treatment. To determine the stomatal opening, epidermal impressions of the leaves were taken. The leaf impressions were obtained with PVC glue applied with a brush on the adaxial and abaxial epidermis of the leaves, where a transparent adhesive tape was placed and fixed on a slide for observation under a compound microscope. The stomatal opening was determined by measuring the opening of the central stomata of 3 visual fields per leaf at 40x magnification with a compound microscope with integrated digital camera and the measurement was made with the AxioVision Rel software. 4.8. The stomatal conductance was recorded with a leaf porometer (SC-1, Decagon Devices, Pullman, WA) and the measurement of the photosynthetic rate was carried out with a foliar $\mathrm{CO}_{2}$ assimilation measurement equipment (LI-6400).

2.6 Preparation of plant material for mass spectrometric profiling

The lyophilized plants were macerated in a porcelain mortar and sieved with a pore mesh of 297 microns (Mesh No. 50). The sieving obtained was placed in microcentrifuge tubes. To each tube was added $2 \mathrm{ml}$ of $80 \%$ ethanol (prepared with absolute ethanol grade HPLC and milliQ water), subsequently they were sonicated for 20 minutes and centrifuged at $13000 \mathrm{rpm}$ for 15 minutes to obtain $10 \mu \mathrm{l}$ of supernatant. The supernatant was filtered in $0.2 \mu \mathrm{m}$ Nylon before its injection to the single quadrupole mass spectrometer (Water SQ Detector). The measurements were made with an electrospray ionization detector (ESI) in positive and negative mode. The spectra were recorded in a range of 15 to $1000 \mathrm{~m} / \mathrm{z}$ (mass/charge), with a run time of 1 minute and scans every 10 seconds. The masses were grouped in $0.1 \mathrm{~s}$ intervals. The masses that showed greater intensity in the different treatments were recorded in box graphs with their standard deviation and a mean test was performed with Tukey at a $95 \%$ probability.

2.7 Statistical analysis

The statistical analys is of the masses was conducted with a randomized block design with 3 and 4 biological replicas. The means are shown with bars representing the standard deviation.

\section{RESULTS AND DISCUSSION}

3.1 Enzymatic activity

Enzymatic activity catalase (CAT), peroxidase (POX), and superoxide dismutase (SOD), was measured with previous quantification of total soluble proteins. The analysis of the antioxidant activity was carried out in an attempt to elucidate the response mechanisms of the reactive oxygen species that are generated when the plants are in a state of stress. It was noted that the total soluble proteins remained at levels comparable to the activity of the enzymes (Fig. 1A). The statistical analys is of the enzymatic activity in the bean plants with the different treatments showed a significant difference with the application of jasmonic acid, which had a high catalase and peroxidase activity (Fig. 1B and 1C). $T$. asperellum promoted high superoxide dismutase activity (Fig. 1D). The lowest enzymatic activity resulted from the application of B. pumilus and the control. This highlights the fact that the high enzymatic activity concurs with the photosynthetic efficiency induced in plants treated with jasmonic acid.

The high antioxidant activity induced by jasmonic acid in bean plants has been observed in other species such as Arabidopsis thaliana, where it was observed that the application at low concentrations increases the antioxidant activity considerably, however, at high concentrations the response is inverse (Maksymiec and Krupa, 2002). 

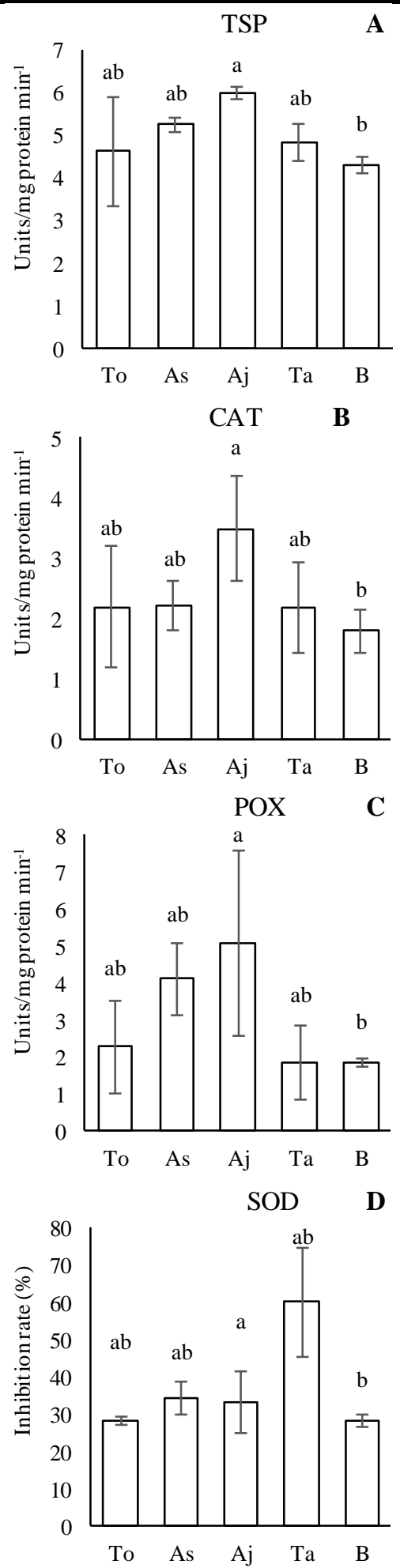

Fig.1: Total soluble proteins (TSP), catalse activity

$(C A T)$, peroxidase $(P O X)$, and superoxide dismutase (SOD) presented in bean plants (Phaseolus vulgaris $c v$.

Pinto Nacional) with the different treatments. To: control plants, As: salycilic acid, Aj: jasmonic acid, Ta:

Trichoderma asperellum, B: Bacillus pumilus. Bars followed by different letters show significant differences according to the test Tukey $(p \leq 0.05)$.
On the other hand, there are several research works that demonstrate the ability of Trichoderma species as activators of antioxidant activity in plants. $T$. virens applied simultaneously with Suillus luteus, in plants of Pinus sylvestris var. Mongolica, increases the enzymatic activity superoxide dismutase in comparison to the enzymatic activity catalase and peroxidase even after thirty days after inoculation (Yin et al., 2014). In this work, T. asperellum applied to bean plants stimulated a high superoxide dismutase activity detectable on the seventh day after its application, not being statistically different in comparison to the rest of the treatments in later days (data not shown). On the other hand, B. pumilus applied to the plants does not induce a high enzymatic activity compared to the control. Previous research shows that the mixture of strains of $B$. pumilus with other species such as B. amyloliquefaciens consis tently induces an increase in enzymatic activity in tomato plants (Solanum lycopersicum L.), which was more noticeable after a confrontation with phytopathogens (Jetiyanon, 2007). This suggests that a high expression of antioxidant activity in some plant species is only visible after the interaction of plants with pathogens.

3.2 Stomatal conductance, photosynthetic rate, and stomatal opening

In order to quantify the effect of the activators on the photosynthetic efficiency of the bean plants, at the same time the stomatal conductance and opening were measured. The results show that the plants treated with jasmonic acid, significantly have a greater stomatal conductance compared to the rest of the treatments (Fig. 2A). The plants treated with jasmonic acid, T. asperellum, B. pumilus and the control were not significantly different in stomatal conductance. Specifically, the greatest difference in conductance was observed in the plants treated with jasmonic acid and B. pumilus, in a range of 65 to $96 \mathrm{mmol} \mathrm{m}^{-2} \mathrm{~s}^{-1}$. The photosynthetic rate was lower in plants treated with B. pumilus $\left(9 \mu \mathrm{mol} \mathrm{CO}_{2} \mathrm{~m}^{-2} \mathrm{~s}^{-1}\right)$ compared with those treated with jasmonic acid $(13 \mu \mathrm{mol}$ $\mathrm{CO}_{2} \mathrm{~m}^{-2} \mathrm{~s}^{-1}$ ) (Fig. 2B). The measurement of the stomatal opening showed that the plants treated with jasmonic acid and $T$. asperellum (1.8 and 1.7 microns) cause a statistically significant greater stomatal opening ( $p<0.05)$ in comparison to the rest of the treatments, where the plants treated with $B$. pumilus were those with the least stomatal opening (1.0 microns) (Fig. 2C).

Previous studies show that jasmonic acid applied exogenously to plants induces a stomatal closure at concentrations higher than $10^{-06} \mathrm{M}$ in monocots such as barley (Metodiev et al., 1996). In legumes such as broad bean, the same effect has been observed in the first minutes or hours of its application (Liu et al., 2005), however, there are no works that prove the effect after 
several days of its application. In this work, the jasmonic acid at $5 \times 10^{-04} \mathrm{M}$ produced an effect of higher stomatal opening in the bean plants 7 days later. The observed effect suggests that the response to stomatal closure in bean plants would be located at higher concentrations of JA.
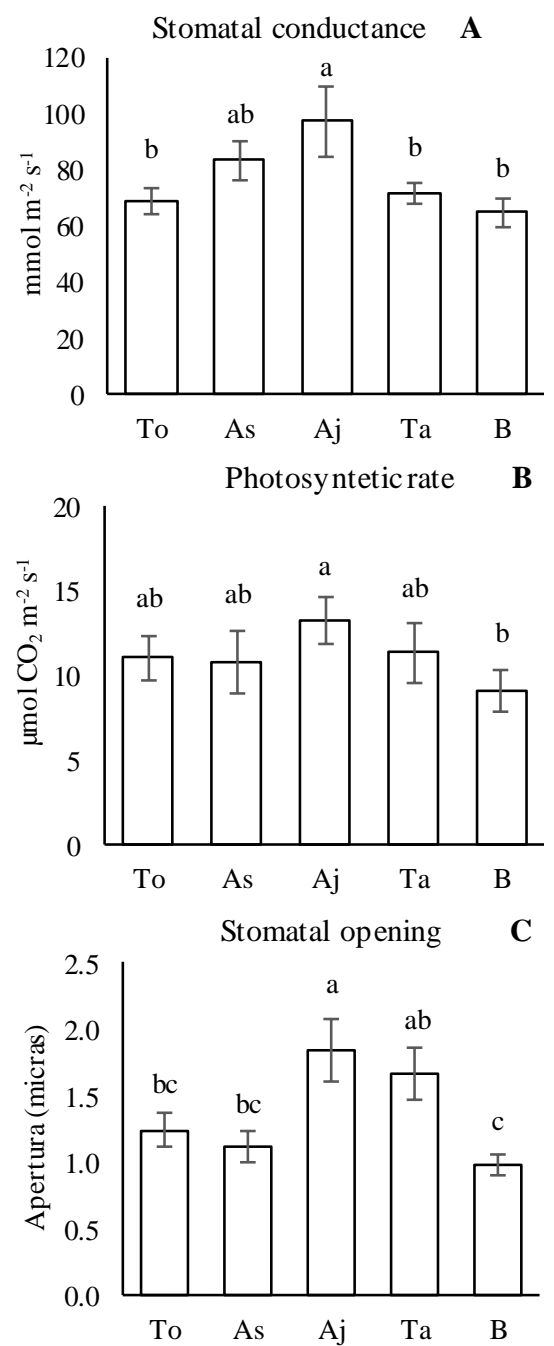

Fig.2: Stomatal opening and conductance, and photosyntetic rate presented in bean plants (Phaseolus vulgaris $c v$. Pinto Nacional) with the different treatments. To: control plants, As: salycilic acid, Aj: jasmonic acid, Ta: Trichoderma asperellum, B: Bacillus pumilus. Bars followed by different letters show significant differences according to the test Tukey ( $p \leq 0.05)$.

3.3 Mass spectral profile

In order to strengthen the evidences of the mechanisms used by the activators, the lyophilized samples of the treated plants were processed for an analysis of the spectral profile of the masses that are induced. The results showed that the most intense masses are located in the range of 135 to 435 mass/charge $(\mathrm{m} / \mathrm{z})$ (Fig. 3A-3E), being the plants treated with $T$. asperellum followed by jasmonic acid, those that visually more intense masses present and in which the m/z 192.3 stands out (Fig. 3A).
T. asperellum A
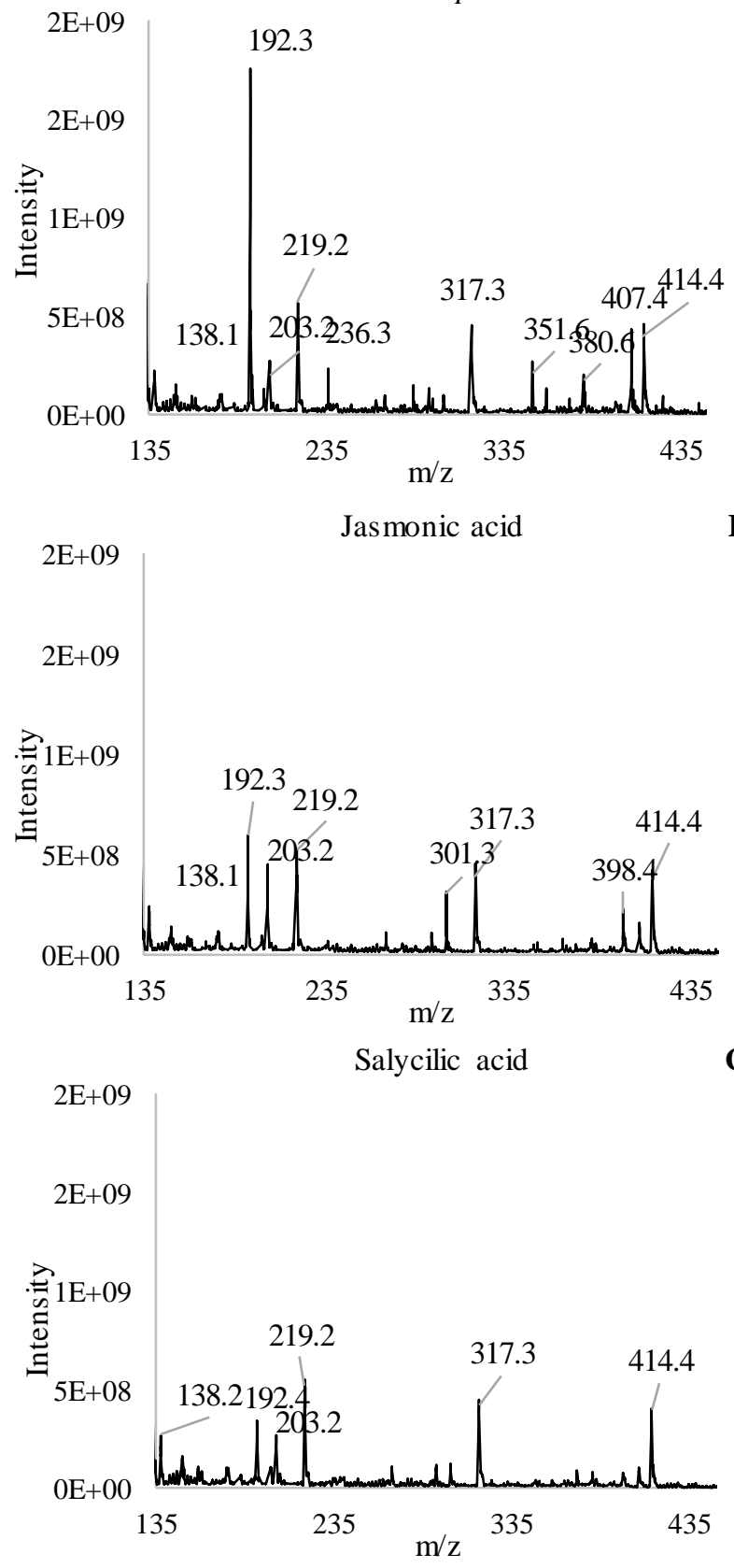

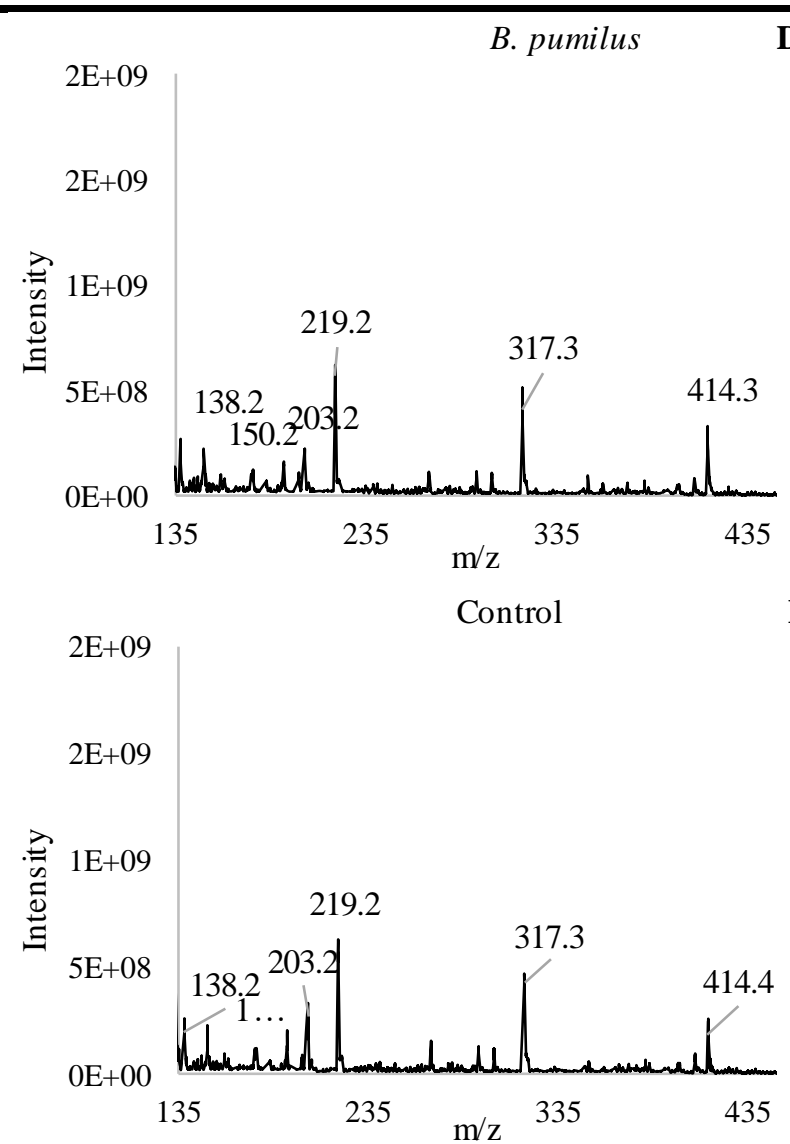

Fig.3: Spectral profile mass/charge $(\mathrm{m} / \mathrm{z})$ with higher intensity presented in bean plants (Phaseolus vulgaris $\mathrm{cv}$.

Pinto Nacional) with the different treatments.

The means test showed that the plants treated with $T$. asperellum present four highly significant masses $(\mathrm{m} / \mathrm{z}$ 192.3, 236.4, 407.4, and 415.4) (Fig. 4A-4D). The mass 415.4 is statistically higher both in the plants treated with T. asperellum and jasmonic acid compared to the rest of the treatments (Fig. 4D). The means test of the most intense masses makes it possible to show that the pattern of the intensities in all the treatments is comparable to the pattern shown by the stomatal behavior and the antioxidant activity, in which it is observed that the plants treated with B. pumilus and the control plants result with statistical inferiority compared to the rest of the treatments.

The alteration of important metabolites for the metabolism of plants by root inoculation with Trichoderma asperelloides has been demonstrated in Arabidopsis thaliana (Brotman et al., 2012). Likewise, numerous studies report that the inoculation of plants with beneficial microorganisms elicits a systemic network that influences the primary metabolism, therefore the initial changes are observed in the levels of carbohydrates and secondarily in the levels of the compounds related to the plant defense (Weston et al., 2012). This suggests that the most intense masses found with statistically significant superiority in the plants treated with T. asperrellum and jasmonic acid would be related to both primary and secondary metabolism, according to what was observed in the photosynthetic activity and antioxidant activity.

\section{CONCLUS ION}

The exogenous application of defense activators in bean plants produced substantial effects. Particularly, jas monic acid and T. asperellum significantly increase antioxidant activity and stimulate a high photosynthetic rate. Similarly, there is a high expression of masses (putative metabolites) when using such activators, which suggests that the primary and secondary metabolism was not negatively affected.

$\mathbf{E}$
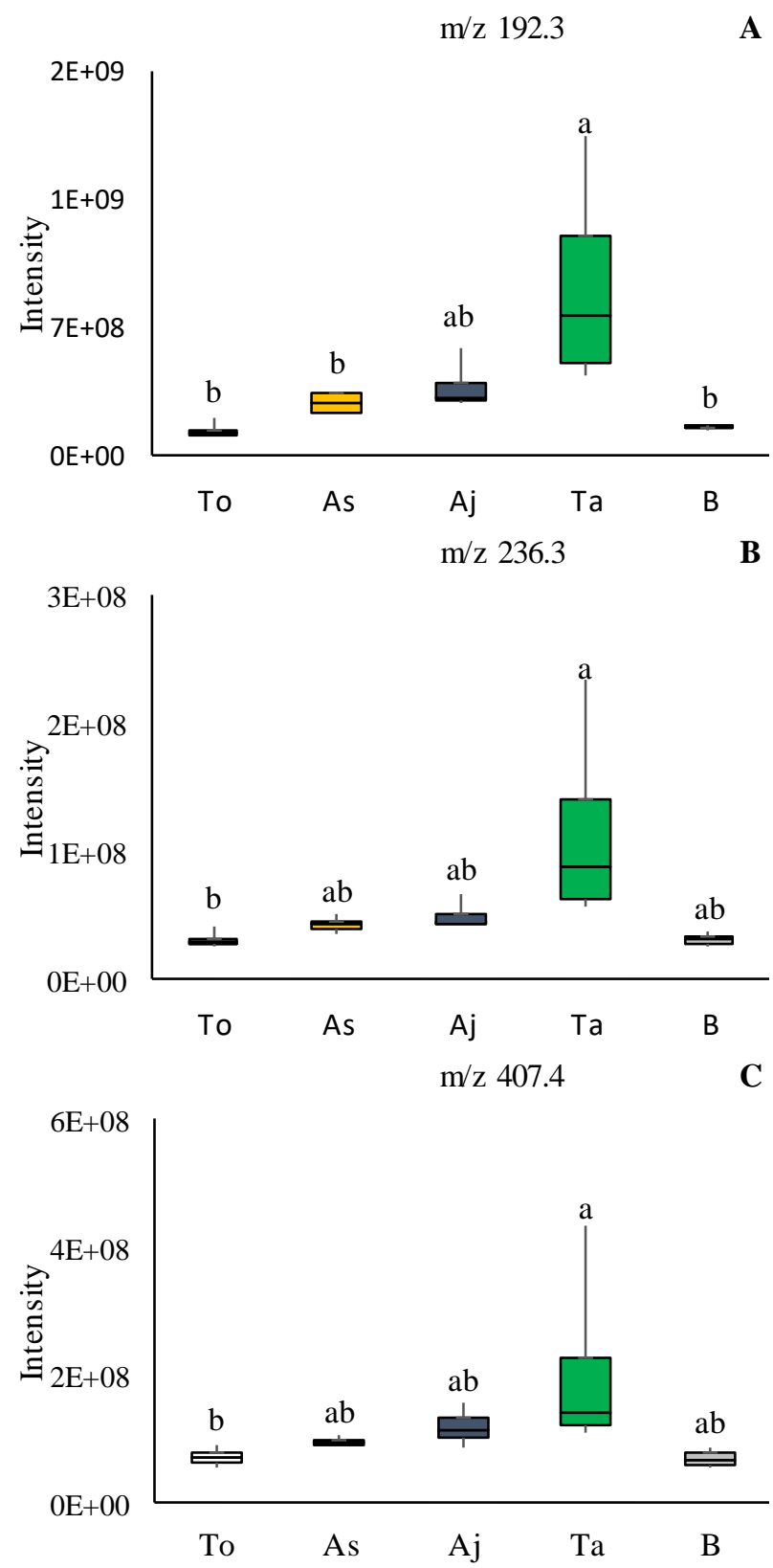
$\mathrm{m} / \mathrm{z} 415.4$

D

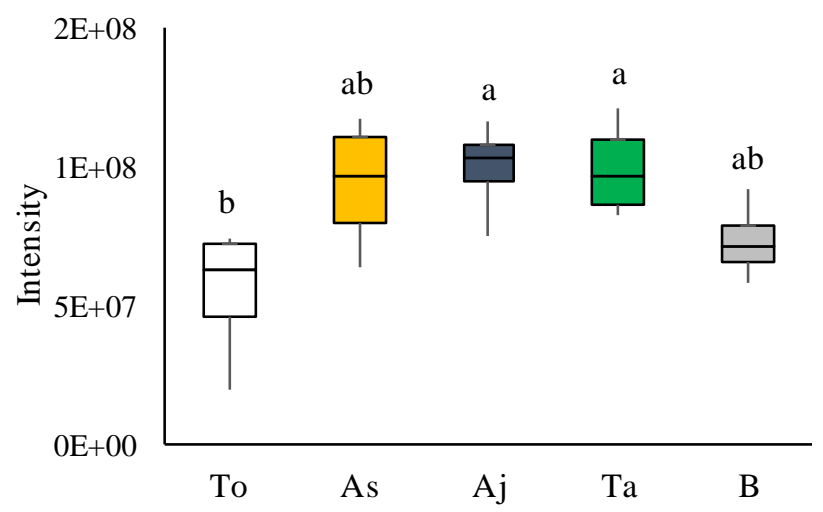

Fig.4: Behavior of mass charge $(\mathrm{m} / \mathrm{z})$ with higher intensity presented in bean plants (Phaseolus vulgaris $\mathrm{cv}$. Pinto Nacional) with the different treatments. To: control plants, As: salycilic acid, Aj: jasmonic acid, Ta:

Trichoderma asperellum, B: Bacillus pumilus. Bars followed by different letters show significant differences according to the test Tukey $(p \leq 0.05)$.

\section{ACKNOWLEDGEMENTS}

We thank Dr. John Paul Délano Frier and Dr. Julio Massange Sánchez for the facilities provided and the advice on mass spectral profiling in the Laboratory of Plant Physiology of the CINVESTAV Unit Irapuato, Guanajuato, Mex.

\section{REFERENCES}

[1] Bisen, K., Keswani, C., Patel, J. S., Sarma, B. K. and Singh, H. B. (2016). Trichoderma spp.: efficient inducers of systemic resistance in plants. In Microbial-mediated Induced Systemic Resistance in Plants, 185-195.

[2] Bolwell, G. P. and Daudi, A. (2009). Reactive oxygen species in plant-pathogen interactions. In Reactive oxygen species in plant signaling, 113-133.

[3] Brotman, Y., Lisec, J., Méret, M., Chet, I., Willmitzer, L. and Viterbo, A. (2012). Transcript y metabolite analysis of the Trichoderma-induced systemic resistance response to Pseudomonas syringae in Arabidopsis thaliana. Microbiology, 158(1), 139-146.

[4] Castillo, F. D., Padilla, A. M., Morales, G. G., Siller, M. C., Herrera, R. R., González, C. N. and Reyes, F.C. (2011). In vitro antagonist action of Trichoderma strains against Sclerotinia sclerotiorum y Sclerotium cepivorum.American Journal of Agricultural y Biological Science 6, 410-417.

[5] Grimmer, M. K., John Foulkes, M. and Paveley, N. D. (2012). Foliar pathogenesis y plant water relations: a review. Journal of experimental botany, 63(12), 43214331.

[6] Guillén-Cruz, R., Hernández-Castillo, F. D., GallegosMorales, G., Rodríguez-Herrera, R., Aguilar-
González, C.N., Padron-Corral, E. and Reyes-Valdés, M. H. (2006). Bacillus spp. como biocontrol en un suelo Infestado con Fusarium spp, Rhizoctonia solani Kuhn y Phytophthora capsici Leonian y su efecto en el desarrollo y rendimiento del cultivo de chile (Capsicum annum L.). Revista Mexicana de Fitopatología, 24, 105-114.

[7] Hafez, E.M. and Seleiman, M.F. (2017). Response of barley quality traits, yield y antioxidant enzymes to water-stress y chemical inducers. International Journal of Plant Production, 11(4), 477-490.

[8] Hayat, Q., Hayat, S., Irfan, M. and Ahmad, A. (2010). Effect of exogenous salicylic acid under changing environment: a review. Environmental y experimental botany, 68(1), 14-25.

[9] Helepciuc, F. E., Mitoi, M.E., Manole-Paunescu, A., Aldea, F., Brezeanu, A. and Cornea, C. P. (2014). Induction of plant antioxidant system by interaction with beneficial y/or pathogenic microorganisms. Romanian Biotechnological Letters, 19(3), 9366-9375.

[10] Jetiyanon, K. (2007). Defensive-related enzyme response in plants treated with a mixture of Bacillus strains (IN937a y IN937b) against different pathogens. Biological control, 42(2), 178-185.

[11] Lin, T.C., Ishizaka, M. and Ishii, H. (2009). Acibenzolar-S-methyl-Induced Systemic Resistance against Anthracnose y Powdery Mildew Diseases on Cucumber Plants without Accumulation of Phytoalexins. Journal of phytopathology, 157(1), 4050.

[12] Liu, X., Shi, W., Zhang, S. and Lou, C. (2005). Nitric oxide involved in signal transduction of Jasmonic acid-induced stomatal closure of Vicia faba L. Chinese Science Bulletin, 50(6), 520-525.

[13] Maksymiec, W. and Krupa, Z. (2002). The in vivo y in vitro influence of methyl jasmonate on oxidative processes in Arabidopsis thaliana leaves. Acta physiologiae plantarum, 24(4), 351-357.

[14] Massange-Sanchez, J. A., Palmeros-Suarez, P. A., Martinez-Gallardo, N. A., Castrillon-Arbelaez, P. A., Aviles-Arnaut, H., Alatorre-Cobo, F. and DélanoFrier, J. P. (2015). The novel y taxonomically restricted Ah24 gene from grain amaranth (Amaranthus hypochondriacus) has a dual role in development y defense. Frontiers in plant science, 6 , 602.

[15] Metodiev, M. V., Tsonev, T. D. and Popova, L. P. (1996). Effect of jasmonic acid on the stomatal $y$ nonstomatal limitation of leaf photosynthesis in barley leaves. Journal of plant growth regulation, 15(2), 7580. 
[16] Moreira, X., Sampedro, L. and Zas, R. (2009). Defensive responses of Pinus pinaster seedlings to exogenous application of methyl jasmonate: concentration effect systemic response. Environmental y Experimental Botany, 67(1), 94-100.

[17] Niu, D., Xia, J., Jiang, C., Qi, B., Ling, X., Lin, S. and Zhao, H. (2016). Bacillus cereus AR156 primes induced systemic resistance by suppressing miR825/825* y activating defense-related genes in Arabidopsis. Journal of integrative plant biology, 58(4), 426-439.

[18] Oliveira, M. D. M., Varya, C. M. R. and Félix, M. R. F. (2016). Induced resistance during the interaction pathogen $x$ plant $y$ the use of resistance inducers. Phytochemistry letters, 15, 152-158.

[19] Pieterse, C. M., Zamioudis, C., Berendsen, R. L., Weller, D. M., Van Wees, S. C. and Bakker, P. A. (2014). Induced systemic resistance by beneficial microbes. Annual review of phytopathology, 52, 347375.

[20] Weston, D. J., Pelletier, D. A., Morrell-Falvey, J. L., Tschaplinski, T. J., Jawdy, S. S., Lu, T. Y. and Karve, A. A. (2012). Pseudomonas fluorescens induces strain-dependent y strain-independent host plant responses in defense networks, primary metabolism, photosynthesis, y fitness. Molecular Plant-Microbe Interactions, 25(6), 765-778.

[21] Winkler, R. (2015). SpiderMass: semantic database creation $\mathrm{y}$ tripartite metabolite identification strategy. Journal of Mass Spectrometry, 50(3), 538541.

[22] Yin, D., Deng, X., Chet, I. and Song, R. (2014). Physiological responses of Pikus sylvestris var. mongolica seedlings to the interaction between Suillus luteus y Trichoderma virens. Current microbiology, 69 (3), 334-342. 